\title{
Intraoperative detection of laparoscopic bladder injury
}

We report a case of bladder perforation during laparoscopic gynaecological surgery that was detected intraoperatively by gaseous distention of the urinary bag. The anaesthetist can help detect intraoperative laparoscopic bladder injury by checking the bladder catheter collection bag for gaseous distension. In this clinical report, gaseous distention of the urinary bag was the only indication of intraoperative laparoscopic bladder injury and resulted in immediate intervention and surgical repair. Intraoperative bladder injury repair will result in decreased surgical morbidity, and if performed laparoscopically may result in decreased hospital stay.

Nous rapportons une perforation vésicale survenue pendant une laparoscopie gynécologique et décelée par la distension gazeuse du sac de collecte urinaire. L'anesthésiste peut aider à déceler la lésion de la vessie en vérifiant si le sac de collecte urinaire est distendu par du gaz. Dans l'observation actuelle, la distension a été le seul indice d'une lésion vésicale peropératoire qui a été réparée immédiatement. La réparation d'une lésion vésicale pendant lintervention réduit la morbidité et sa réalisation par laparoscopie diminue la durée du séjour hospitalier.

Laparoscopy has developed from a solely diagnostic procedure to that of a therapeutic operation. However, it has its own associated complications, ${ }^{1}$ and we describe a case of bladder perforation during laparoscopic-assisted vaginal hysterectomy. This complication was detected intraoperatively by gaseous distention of the urinary bag. Early detection resulted in immediate intervention and repair.

\section{Key words}

COMPLICATIONS: cystotomy;

SURGERY: laparoscopy.

From the Department of Anesthesiology, University of

Kentucky Medical Center, University of Kentucky, Lexington, Kentucky, U.S.A.

Address correspondence to: Dr. Paul A. Sloan, Department of Anesthesiology, University of Kentucky Hospital, 800 Rose Street, Lexington, KY 40536-0084 U.S.A.

Accepted for publication Ist January, 1995.

\section{Case report}

An otherwise healthy 45-yr-old woman with uterine leiomyoma and suffering from uterine bleeding presented for laparoscopic-assisted vaginal hysterectomy. Past surgery included removal of uterine fibroids. Physical examination was unremarkable; she weighed $80 \mathrm{~kg}$ and was 168 $\mathrm{cm}$ tall. Laboratory variables were within normal limits.

The monitored $\left(\mathrm{SpO}_{2}, \mathrm{NIBP}\right)$ patient was premedicated in the holding room with midazolam $2 \mathrm{mg} \dot{i}$ and a lumbar epidural catheter was placed for postoperative analgesia. Anaesthesia was induced with thiopentone and fentanyl, and the tracheal intubation facilitated with vecuronium. Preservative-free morphine $(3.5 \mathrm{mg}$ ) was added to the lumbar epidural catheter. Anaesthesia was maintained with $65 \%$ nitrous oxide in oxygen, and isoflurance 1.5-2\%. Controlled ventilation maintained end-tidal $\mathrm{CO}_{2}$ at $33 \mathrm{mmHg}$ throughout surgery. Monitoring consisted of NIBP, ECG, $\mathrm{SpO}_{2}, \mathrm{ETCO}_{2}$, ETAA, and temperature.

Laparoscopy was begun with insertion of a $10-\mathrm{mm}$ trocar infraumbilically, two $12-\mathrm{mm}$ trocars lateral to the umbilicus, and a 5-mm trocar inserted under direct laparoscopic visualization. Surgery and anaesthesia proceeded uneventfully. Urine output was $50 \mathrm{ml}$ during the first hour, but after two hours there was balloon-like distention of the bladder catheter bag with gas. The bag contained no urine or blood and the bladder was then filled with methylene blue. Examination through the laparoscope revealed intraperitoneal extravasation of the dye which confirmed the diagnosis of bladder perforation. The laparoscopic procedure was abandoned. At laparotomy, two $5 \mathrm{~mm}$ cystotomies were noted through the dome of the bladder which appeared to be caused by the 5 $\mathrm{mm}$ trocar. They were repaired and a TAH BSO was completed uneventfully. The patient recovered from anaesthesia without incident.

A bladder catheter remained in place postoperatively for seven days. The patient spiked a temperature on postoperative day \#1 and was given broad spectrum antibiotics with defervescence. The remained of her hospital stay was uneventful.

\section{Discussion}

Operative laparoscopy has been practiced for over $40 \mathrm{yr}$ and is now one of the most frequent operations to be 
performed in gynecologic surgery. While this surgical technique is associated with reduced morbidity and decreased hospital stays compared with open procedures, it is associated with complications. These complications have been classified as pneumoperitoneum-related, positional-related, and trocar-related ${ }^{\prime}$. Major traumatic complications include laceration of the bowel, injury of large blood vessels, perforation of the stomach and bladder, as well as ureteral injuries. Urological injuries are a known complication of laparoscopic surgery, and their frequency has been estimated to be $<1: 2000$ cases. Early warning signs include haematuria, discharge of clear fluid into the operating field, and the presence of air or carbon dioxide in the bladder catheter bag. ${ }^{2}$

Our clinical report describes the first case of intraoperative laparoscopic bladder injury detected by gaseous distention of the urinary bag that resulted in immediate intervention and surgical repair. This early intraoperative detection allowed immediate repair and avoided the need for reoperation had the injury not been detected until after surgery.

The first two reported cases of laparoscopic-related bladder injuries appeared in $1974 .{ }^{3}$ Both injuries were caused by the laparoscopic trocar. One bladder perforation was visualized immediately through the laparoscope and repaired by open laparotomy, and the other case was recognized several hours later and required open surgical repair. It is estimated that approximately half of the laparoscopically induced bowel injuries are not detected at the time of surgery, and are diagnosed when signs and symptoms of peritonitis develop postoperatively. ${ }^{4}$ Similarly, bladder injuries are typically detected in the postoperative course, when the patient may develop abdominal tenderness, nausea, vomiting, and oliguria. It is evident that early diagnosis of bladder injury in the operating room may significantly decrease morbidity in these patients. Because signs of peritoneal irritation were blunted by general anaesthesia, the anaesthetist must be vigilant in observing the bladder bag for gas or blood.

Intraoperative detection of laparoscopic bladder injury resulted in immediate repair of the bladder perforation by open laparotomy. While this is a standard form of surgical repair, intraperitoneal bladder injuries can be repaired laparoscopically, with the patient benefiting from a shortened hospital stay and decreased postoperative pain. Iatrogenic bladder cystotomies are usually single perforations, and located in areas amenable to laparoscopic repair, such as posterior bladder wall, or dome of the bladder. ${ }^{5}$

The gaseous distension of the bladder bag in our patient was highly suspicious for intraoperative bladder injury. An additional test to corroborate our suspicions would have been to measure the $\mathrm{PCO}_{2}$ of this gas.
In conclusion, bladder injuries associated with trocar needle insertion during laparoscopy continue to occur in spite of increasing physician experience and the use of safeguards. ${ }^{4}$ The anaesthetist can help to detect intraoperative laparoscopic bladder injury by checking the bladder catheter collection bag for gaseous distention. Intraoperative detection of bladder injury will result in early intraoperative repair that may be carried out through the laparoscope.

\section{References}

1 Loffer $F D$, Pent $D$. Indications, contraindications and complications of laparoscopy. Obstet Gynecol Surv 1975; 30: 407-26.

2 Font GE, Brill AI, Studhldreher PV, Rosenzweig BA. Endoscopic management of incidental cystotomy during operative laparoscopy. J Urol 1993; 149: 1130-1.

3 Georgy FM, Fetterman HH, Chefetz MD. Complication of laparoscopy: two cases of perforated urinary bladder. Am J Obstet Gynecol 1974; 120: 1121-2.

4 Yuzpe AA. Pneumoperitoneum needle and trocar injuries in laparoscopy: a survey on possible contributing factors and prevention. J Reprod Med 1990; 35: 485-90.

5 Parra RO. Laparoscopic repair of intraperitoneal bladder perforation. J Urol 1994; 151: 1003-5. 